\title{
GUI FOR VIBRATION PREDICTIONS DURING RTB OF A SERVICED HELICOPTER
}

\author{
Kothara Srinivasa Rao \\ Department of Mechanical Engineering \\ Jawaharlal Nehru Technological University, Kakinada \\ Andhra Pradesh, India.
}

\begin{abstract}
Vibrations on helicopter induced in Main Rotor System and Tail Rotor System due to in plane unbalanced masses and out of plane rotation of rotor blades. Rotor Track and Balance (RTB) of helicopter is performed to reduce vibrations of helicopter. Number of vibration flights will increase if RTB is not optimised. Main Rotor and Tail Rotor vibrations can be reduced by predicting the vibrations prior to flight using Multiple Linear Regression and Analysis of Variance (MLR \& ANOVA). The Inputs for the Multiple Linear Regression would be in terms of mass changes, track changes and tab changes based on established sensitivities of these Inputs and cross sensitivities between them. The outputs are vibration changes of Main Rotor / Tail Rotor. Change in vibrations is the difference between the vibration values of two successive flights / ground runs. For Main Rotor, there are 12 inputs to adjust 2 outputs (MR Lateral and MR Vertical), for Tail Rotor, there are 8 inputs to adjust 2 outputs (TR Radial and TR Axial) for satisfactory vibrations during ground run, HOGE and two steady speed forward flight regimes. In this Research work, three types of Regression Models for Main Rotor System and Two types of Regression Models for Tail Rotor System were made to predict the vibrations of helicopter prior to ground run or flight. The Regression Coefficients were evaluated using MatLab and models were generated. ANOVA is performed for regression models and found satisfactory. The Coefficient of Regression (Multiple-R / $R^{2}$ ) values obtained are more than 0.9 . The results of the regression indicated that the model was a significant predictor of vibration changes. Graphical User Interface (GUI) using Regression Models is made for vibration predictions of Main Rotor and Tail Rotor Vibrations of Serviced helicopter. This research work recommends for the implementation of Multiple Linear Regression and its applications for vibration predictions of Serviced helicopters to reduce vibration flights.
\end{abstract}

Keywords - Rotor Track and Balance, Vibration, Helicopter, Multiple Linear Regression, ANOVA, Main Rotor, Tail Rotor, RTB, GUI.

\author{
A.Gopala Krishna, Professor, \\ Department of Mechanical Engineering \\ Jawaharlal Nehru Technological University, Kakinada \\ Andhra Pradesh, India
}

\section{INTRODUCTION}

Helicopter can take off and land vertically as well as ability to hover. These characteristics enable it for rescue operations and military applications. Helicopter Major Servicing is carried out on a time based maintenance routine presently and intent is to adapt Condition based maintenance in future. Helicopter vibrations are predominant due to Main Rotor and Tail Rotor Improper blade track is another source of main rotor vibrations. The RTB process takes care of $1 /$ rev vibrations of the rotor. Vibration magnitudes (in inch per second) and phase angle (as clock angle) are recorded during ground run and flights. During RTB process, the corrections - mass, tracking link / track and trim tabs are used to determine vibration changes in successive flights. The RTB process requires several no. of flights to bring the vibrations to the acceptable levels if it is not optimized.

\section{MR and TR Vibrations}

Helicopter Main Rotor vibrations are in the vertical and lateral planes. A vertical vibration is a result of unequal lift produced by the main rotor blades. This unequal lift can be a result of blade chord profile variances from one blade to the next or improper adjustment of Tracking Links and Trim Tabs. These constitute the most common causes of vertical vibration. $1 / \mathrm{rev}$ unbalance of tail rotor is caused due to weight scatter on the tail rotor blade pair assembly or due to blades not rotating in the same plane. The unbalance caused due to weight scatter results in radial or in-plane unbalance of the rotor and vibration due to out of plane rotation causes the axial unbalance. There is also a cross sensitivity between the radial and axial unbalance.

The rest of the paper is organized as follows. Problem statement is explained in Section-II, Literature Survey in Section-III, Methodology, Experimental setup and Vibration Data Acquisition, MLR for RTB of helicopter are explained in Section-IV to VI. Modelling, Validation and Testing of Vibration data in Section-VII. Results, Future Work, Acknowledgements and References are explained in SectionVIII to XI. 


\section{International Journal of Engineering Applied Sciences and Technology, 2021 Vol. 6, Issue 1, ISSN No. 2455-2143, Pages 265-277 \\ Published Online May 2021 in IJEAST (http://www.ijeast.com)}

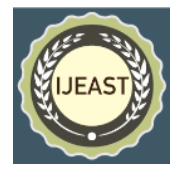

\section{PROBLEM STATEMENT}

The helicopter uses flexible rotating wings which provide Lift, Propulsion and Control forces. Vibrations at $1 /$ rev (1P, 1R) manifests due to mass differences between the Main Rotor blades and differences in aerodynamic forces on the blades. RTB process is performed to bring the $1 / \mathrm{rev}$ vibrations to acceptable limits in identified steady flight regimes of a helicopter. The problem here is large no. of ground runs and flights for getting acceptance of helicopters and the difficulty in manual calculations of input parameters (mass changes, track changes and tab changes) to obtain satisfactory output (change in vibrations) during RTB process. For main rotor, there are 12 input parameters to adjust 2 outputs (MR Lateral and Vertical) and for Tail Rotor, there are 8 inputs to adjust 2 outputs (TR Radial and TR Axial) for satisfactory vibrations during ground run, HOGE and two steady speed forward flight regimes. Change in vibrations is the difference between the vibration values of two successive flights / ground runs. During each flight / ground run, the main rotor vibrations magnitude (i.e., velocity in ips) and phase angle (i.e., clock angle) are recorded. Number of vibration flights will increase if RTB process is not optimised. The RTB process can be optimised using Multiple Linear Regression Models by prediction of change in vibration before vibration flight. The methodology adopted for vibration predictions using Multiple Linear Regression is shown in Fig-1.

\section{LITERATURE SURVEY}

Minitab provides a full set of analysis outputs within the regression tool to allow the researcher to evaluate regression equations and determine which independent variables provide the best predictors of the dependent variable. The Minitab output and residual graphs are very clear and easy to read, and are easy to copy and paste into final reports to produce a polished presentation. [1]. Multiple Linear Regression (MLR)based spring durability models were established for predicting the fatigue life of automotive coil springs based on the vertical vibrations of the vehicle and natural frequencies of the vehicle suspension system. The highest coefficient of determination at 0.8820 was obtained for the Morrow MLR-based spring durability model, with the mean square error of 0.5855 . This indicates that more than $80 \%$ of the variability in fatigue life of automotive coil spring is described by the models. The models were validated by comparing the fatigue life values predicted by the models with those predicted from strain measurements. The results show a good agreement between the predicted and experimental values, indicating the suitability of these models in predicting the fatigue life of automotive coil springs [2]. The synthesis of loads on helicopter dynamic components using linear regression in the azimuth domain was improved including the standard flight state and control parameters as candidate predictive variables. The effects of these changes were evaluated in building load synthesis models using linear regression techniques to predict main rotor pitch link loads of 160 representative level flight runs selected from a Blackhawk flight strain survey. It was shown that the inclusion of flight state and control parameters within the model training data improved the predictive accuracy of the model. [3]. Patent analysis analyses the patent documents using text mining and statistics. A multivariate multiple regression modelling in order to efficiently conduct our technology analysis using the patent documents related to three-dimensional printing technology was done [4]. Multivariate multiple linear regression analysis (MMLR) based on principal component scores to investigate relations between two variable data sets in different areas of research, the Principal Component Analysis (PCA) was applied to predictor variables to avoid multicollinearity problem [5]. The effect of departure from Normality of measurement error and the small sample properties of the estimators are studied using a Monte-Carlo simulation study. It is observed that the incorporation of additional information in the form of exact linear restrictions provides better estimators [6]. One of the most important and common question is if there is statistical relationship between a response variable (Y) and explanatory variables $\left(\mathrm{X}_{\mathrm{i}}\right)$. An option to answer this question is to employ regression analysis. There are various types of regression analysis. All these methods allow us to assess the impact of multiple variables on the response variable. Test of hypotheses is to describe correlations or to model relationships (regression) within the data. One way to account for is to compute $\mathrm{p}$-values for a range of possible parameter values. The range of values, for which the $\mathrm{p}$-value exceeds a specified alpha level (typically 0.05) is called confidence interval. An interval estimation procedure will, in $95 \%$ of repetitions produce limits that contain the true parameters. The goal in any data analysis is to extract from raw information the accurate estimation. Linear regression is the procedure that estimates the coefficients of the linear equation, involving one or more independent variables that best predict the value of the dependent variable which should be quantitative. [7]. 'Maximum Correlation Modelling' (Constrained Canonical Correlation Analysis) is maximizing the correlation between the two sides of the model equation which least squares approach to the problem is inadequate as it produces models which are not scale invariant [8]. Multivariate multiple regression, canonical correlation, and redundancy analysis are compared in terms of their analytical capabilities in behavioral research to assist analysts in selecting among the three procedures [9]. Modelling of energy consumption as a key tool to reduce energy consumption and emissions. Regression models can be used to estimate the total energy consumption in the early stages of the design when different building schemes and design concepts are being considered. A total of 17 key building design variables and 7 building shapes were identified and considered as inputs in the regression models. The coefficient of determination R2 varies from 0.94-0.95 indicating that 94 to $95 \%$ of variation in annual building 
energy consumption can be explained by change in 17 parameters. The difference between regression predicted and DOE-2 simulation annual use building energy consumption are largely within 5\%. The regression model act as prediagnostic tool to predict the energy performance in the office buildings [10]. A regression model to predict the heat energy demand, based on the factors of the building global heat loss coefficient $(\mathrm{G})$, the south equivalent surface (SES) and the difference between the indoor set point temperature and the soil-air temperature that influence a buildings heat consumption. Multiple dynamic simulations were carried out in order to determine the values of the inputs and output data of the future prediction model. A multiple regression prediction model was developed for future predictions. Detailed error analysis showed that the model presents a very good accuracy (correlation coefficient of R2 $=0.9744$, 90\% of the samples have less than $20 \%$ relative error) [11]. Among the statistical models, the linear regression analysis has shown promising results because of the reasonable accuracy and relatively simple implementation when compared to other methods [12]. A machine learning model performs deep regression of raw sensor data obtained from flight conditional indicators (CI). Deep neural network of fully connected layers (DNN) performs high-dimensional and non-linear multivariate regression to reconstruct raw accelerometer data [13]. A formulation for assessing bond strength in sound and corroded steel bars, developed by applying multiple linear regression to a database containing the results of over 650 bond tests. The tests were drawn from a prior study of the authors and the literature. The prediction intervals for this new bond strength formulation are given. [14]. Autoregressive model is an easily implementable and computationally efficient, ARX (autoregressive with exogenous, i.e., external, inputs) time and temperature indexed model for $1 \mathrm{~h}$ ahead building thermal load prediction. Results demonstrated that the performance of a properly indexed ARX model is better than that of nonindexed models and comparable to that of the BPNN. ARX model consists of only seventy coefficients stored, with ten coefficients accessed at a time and used in a simple linear ARX equation. [15]. The structure and statistical dependencies of a database of 150 existing helicopters are investigated by multivariate regression method capable of automated computation of regression functions for a variety of input and output parameters. Additionally a minimum degree of complexity of the regression function is estimated by hypothesis testing. A polynomial regression model was chosen. Statistical methods are well suited for the early stages of helicopter design if a sufficiently large database is available to base the calculations on [16].

\section{IV.METHODOLOGY}

The Methodology of this research involves understanding the Rotor Track and Balance (RTB), Main Rotor, Tail Rotor vibration data analysis of serviced helicopters and modeling
Multiple Linear Regression equations with appropriate dependent and independent variables for predicting vibrations. Independent variables are vibration corrections applied during RTB i.e., mass changes (in grams), track link changes (in flats) / track split (in mm) and tab adjustments (in degrees). The dependent variables are change in vibrations (in ips) of main rotor, tail rotor during identified steady flight regimes of a helicopter. The coefficients of regression equation model are evaluated using MatLab programming. Evaluation of regression equation, Multiple $\mathrm{R}, \mathrm{R}^{\wedge} 2$ is done using data analysis of R-language / ms-excel. Finally, the regression model is used for prediction of vibrations. The regression equation used in this study is as below:

$$
Y_{1}=\beta_{0}+\beta_{1} X_{1}+\beta_{2} X_{2}+\beta_{3} X_{3}+\beta_{4} X_{4}+\delta_{1} \text {----- (1) }
$$

Eqn (1) represents regression model with one dependent parameter and four independent parameters, where $Y_{1}$ is change in vibration in ips, $X_{1}, X_{2}, X_{3}, X_{4}$ are input corrections, $\beta_{0}, \beta_{1}, \beta_{2}, \beta_{3}, \beta_{4}$ are regression coefficients and $\delta_{1}$ is a bias parameter. This equation is used to train the vibration data of helicopter and obtain the regression model to predict MR, TR vibrations / corrections in order to reduce vibrations and number of flights.

Fig-1 shows the flow chart of the methodology adopted for main rotor vibration predictions of helicopter using Multiple Linear Regression.

\section{EXPERIMENTAL SETUP AND VIBRATION DATA ACQUISITION}

Helicopter Main Rotor vibrations are in the vertical and lateral planes. A vertical vibration is a result of unequal lift produced by the main rotor blades or out of plane rotation. Lateral vibrations are due to in plane unbalance of the rotor masses. Similarly, the tail rotor vibrations are in the Axial and Radial planes of tail rotor. Axial vibration is a result of out of plane rotation and Radial vibrations are due to in plane unbalance of the rotor masses. Clearance Form is the document which gives the details of vibration snags and rectification action taken during each ground run / flight. The Clearance forms were analyzed and MR-Lateral, Vertical, TR Radial, Axial vibrations observed during Ground, HOGE, two steady speed forward flight regimes with corrections given were tabulated. Let $\mathrm{Y}_{1}$ and $\mathrm{Y}_{2}$ be the vibrations recorded before and after giving correction of mass, $\mathrm{M}_{1}$. The response of helicopter to correction is change in vibration, $\Delta \mathrm{Y}$ equal to $\mathrm{Y}_{2}-\mathrm{Y}_{1}$. The acceptable limit of vibration is below 0.3ips for main rotor and tail rotor i.e., $\mathrm{Y}_{2}$. Input corrections applied to control the helicopter vibrations in different regression models are shown in Table-1. Fig-2 shows the Vibration Data Acquisition system. Fig-3 shows the Location of components for vibration data acquisition. Fig-4 shows the Cause and Effect Diagram (Quality Control Tool) to identify the components, factors causing vibrations in the helicopter. 


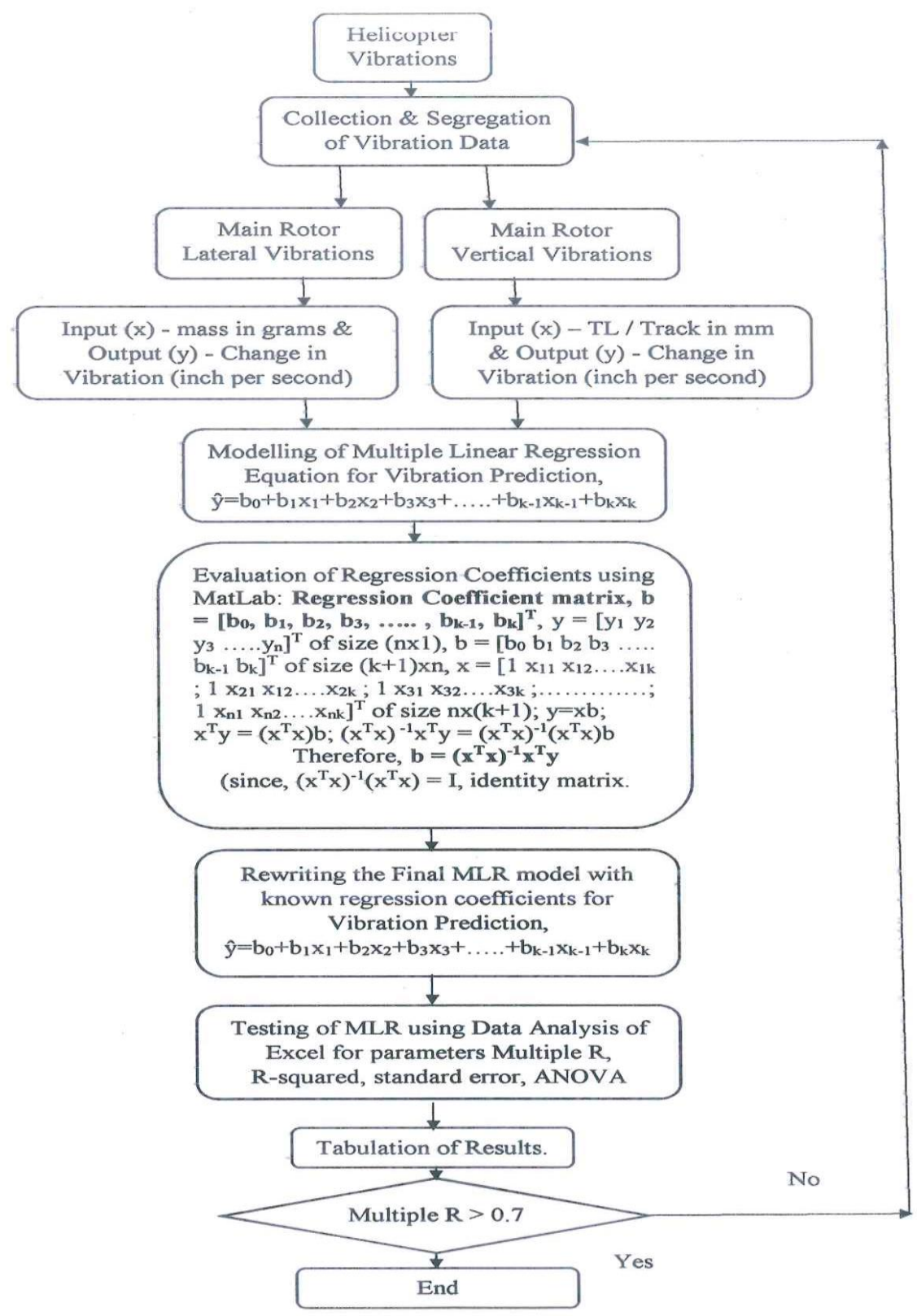

Flow chart for Multiple Regression Method of Vibration Prediction of Helicopter

Fig-1: Flowchart for Multiple Linear Regression Method of Vibration Predictions of Helicopter using MatLab and Data Analysis of Excel.

Table - 1: Input corrections to control the helicopter vibrations (Outputs) in Regression Models.

\begin{tabular}{|c|c|c|c|}
\hline $\begin{array}{c}\text { Sl. } \\
\text { No. }\end{array}$ & Type of Vibrations & $\begin{array}{c}\text { Inputs to Regression } \\
\text { Model }\left(\mathbf{X}_{\mathbf{i}}\right)\end{array}$ & $\begin{array}{c}\text { Outputs } \\
\text { (Prediction of Vibrations, } \hat{\mathrm{Y}} \text { ) }\end{array}$ \\
\hline 1 & Main Rotor Lateral - Ground & Mass, m (in grams) & Change in Vibration, $\Delta \mathrm{V}$ (in ips) \\
\hline 2 & Main Rotor Lateral - Flight & Mass, m (in grams) & Change in Vibration, $\Delta \mathrm{V}$ (in ips) \\
\hline 3 & Main Rotor Vertical - Ground & Tracking Link (in flats) & Change in Vibration, $\Delta V$ (in ips) \\
\hline 4 & Tail Rotor - Axial - Flight & Pitch Link (in flats) & Change in Vibration, $\Delta V$ (in ips) \\
\hline 5 & Tail Rotor - Radial - Flight & Mass, m (in grams) & Change in Vibration, $\Delta V$ (in ips) \\
\hline
\end{tabular}

Hence, reduced vibration in next flight is $\mathrm{Y}_{2}=\mathrm{Y}_{1}-\Delta \mathrm{Y}$. Input mass is in grams and track is in $\mathrm{mm}$. 
A. Block Diagram of Vibrations, Data Acquisition procedure and Vibration Parameters:

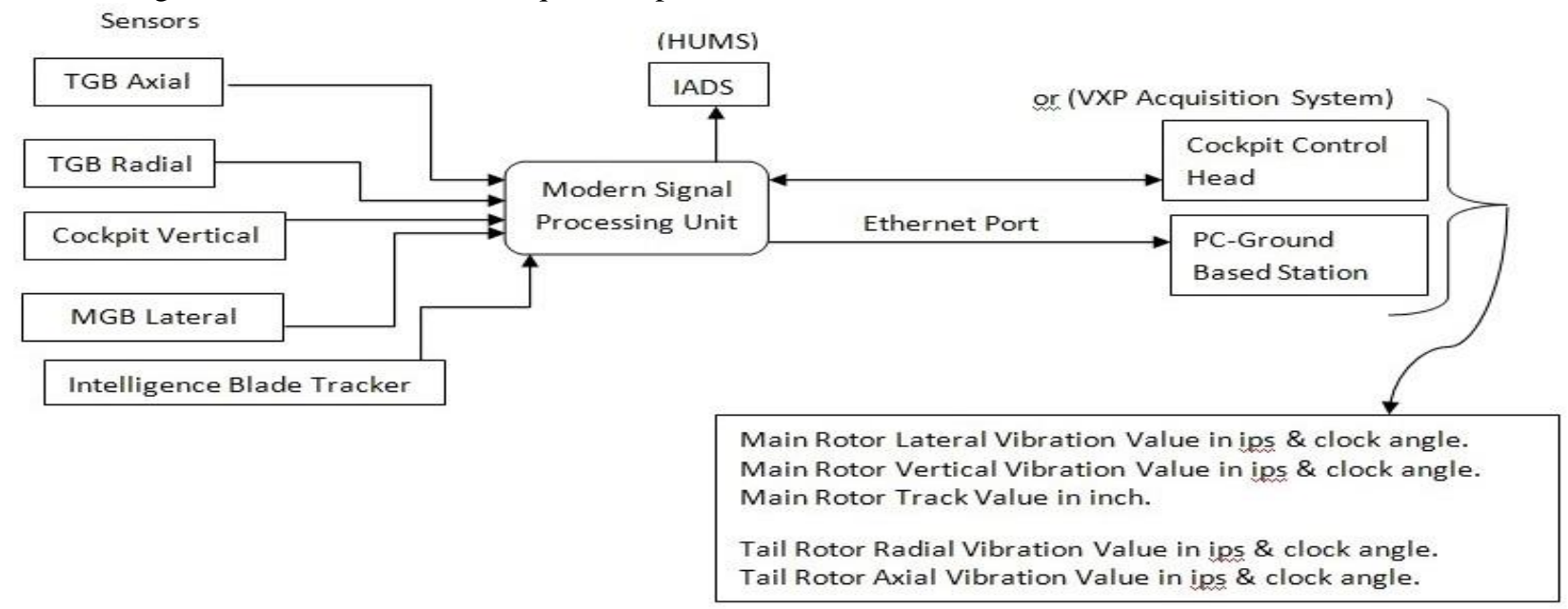

Experimental Setup of Rotor Track and Balance Data Acquisition from Servicing heptr.

Fig-2: Block Diagram of Vibration Acquisition System

B. Experimental Setup for Vibration Data Acquisition:

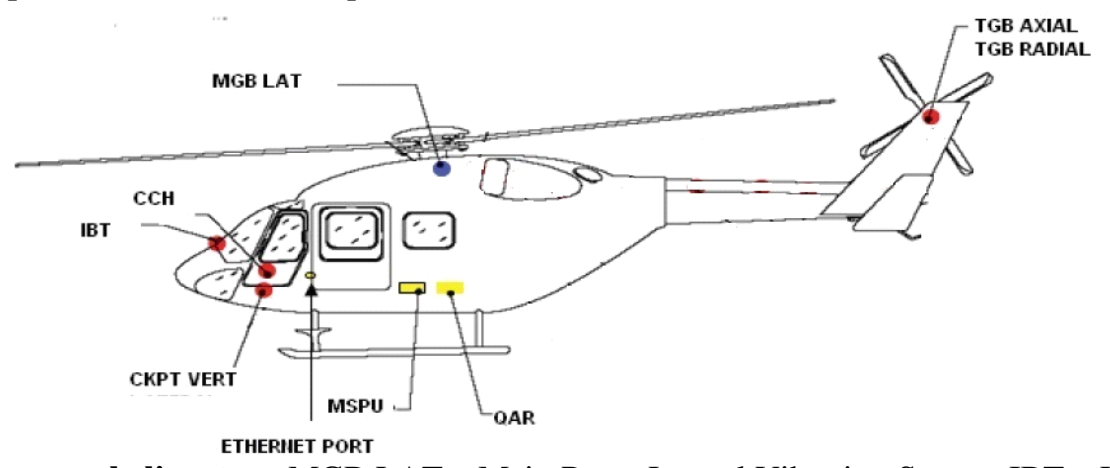

Location of Sensors on helicopter - MGB LAT - Main Rotor Lateral Vibration Sensor, IBT - Intelligent Blade Tracker, CKPT VERT - Cockpit Vertical, TGB AXIAL - TR Vibrations Axial Sensor, TGB RADIAL - TR Vibrations Radial Sensor.

Fig-3: Vibration Data acquisition from Helicopter with Components, their Location \& Block Diagram.

C. Root Cause Analysis for Vibrations in Helicopter:

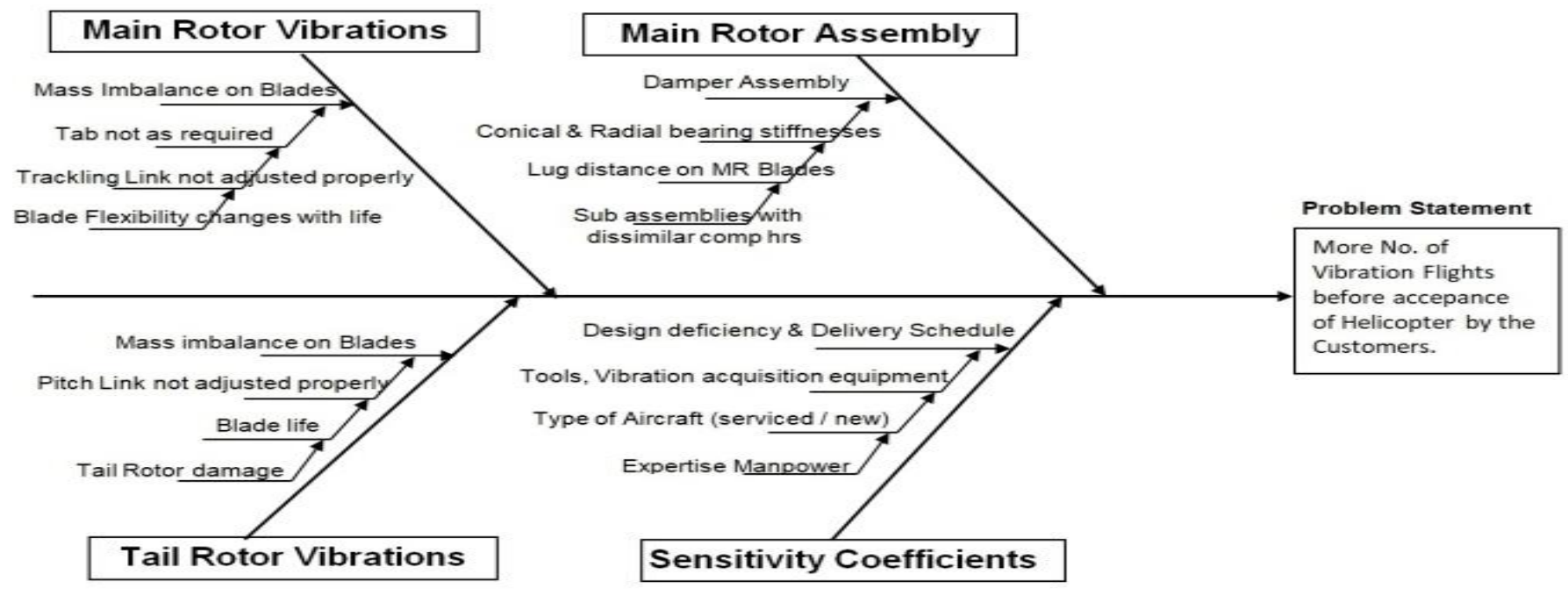




\section{International Journal of Engineering Applied Sciences and Technology, 2021 \\ Vol. 6, Issue 1, ISSN No. 2455-2143, Pages 265-277 \\ Published Online May 2021 in IJEAST (http://www.ijeast.com)}

Fig-4: Fish Bone Diagram (Cause and Effect Diagram) - QC Tool

\section{MULTIPLE LINEAR REGRESSION FOR ROTOR TRACK AND BALANCE OF HELICOPTER}

The Problem of Multiple Inputs and Multiple Outputs for Controlling Vibrations on Helicopter can be solved by using Multiple Linear Regression. For Main Rotor, there are 12 inputs to adjust 2 outputs (MR Lateral and Vertical vibrations). For Tail Rotor, there are 8 inputs to adjust 2 outputs (TR Radial and Axial). Multiple Linear Regression (MLR) or Multivariate Linear Regression (MVLR) methods can be used for prediction of vibrations. Three types of Regression Models for Main Rotor System and Two types of Regression Models for Tail Rotor System were made to predict the vibrations of helicopter. Flowchart of regression model for Main Rotor Vibrations is shown in Fig-1.

For the present case, the regression coefficients of model for vibration predictions were calculated using MatLab software. Table-2 shows the Matlab code used for evaluation of regression coefficients using MatLab. ANOVA is performed for regression models. The process of modeling with MLR / MVLR begins with identification of input parameters and the output to be predicted by the model. Here, MLR for RTB process is used to predict the MR or TR vibrations with input parameters in the form of mass (in grams), tracking link (as flats), pitch link (as flats), track(mm). A MLR models the transfer function between the adjustment parameters and vibrations of the main rotor and tail rotors. The vibration data and corrections given during RTB of 14 helicopters were processed to obtain input and output pairs and were used to develop a Regression Model with the MatLab. Corrections to be given for a new vibration conditions were predicted by using the Regression Model. The MLR vibration predictions for given inputs were found to be satisfactory. The present study is based on the Servicing helicopter experimentation and the vibration history of helicopters.

\section{MODELLING, VALIDATION AND TESTING OF VIBRATION DATA}

Data was trained in Matlab. The regression coefficients were found out using MatLab. Model is prepared using obtained regression coefficients for prediction of vibration predictions for given input corrections for Main Rotor and Tail Rotor during regimes - ground run, HOGE and two steady speed forward flight regimes. MLR Model was obtained based on the Inputs (mass, track link, tab, track) and obtained outputs (MR and TR Vibrations). Five types of MLR models were generated for vibration predictions in different regimes of helicopter using MatLab. The MLR models are obtained from vibration data - MR \& TR. Validation and Testing was done using data analysis software - Minitab / Excel. Table-2 shows the MatLab code for generation of Regression Model. MLR simulation RTB Data / Results \& Model of each case / identified regime were shown below:

Case-1: Multiple Linear Regression Model for Prediction of Main Rotor Lateral Vibrations during Ground Run (Xi - Mass added / removed on MR Blades are inputs and $\Delta \mathrm{Y}-$ Change in MR-Lateral Vibrations are outputs for generating Regression Model using MatLab).

Table-3: Inputs and outputs to MatLab for generate MLR model predicting the MR Lateral Vibrations during ground

\begin{tabular}{|c|c|c|c|c|c|}
\hline \multirow{2}{*}{$\begin{array}{c}\text { Trial } \\
\text { No. }\end{array}$} & \multicolumn{4}{|c|}{ MR Lateral - Ground (Mass inputs) } & Outputs \\
\cline { 2 - 6 } & X1 & X2 & X3 & X4 & YG \\
\cline { 2 - 6 } & Red & Yellow & Blue & Green & $\Delta$ YG \\
\hline 1 & 0 & -15 & 0 & 15 & -0.463 \\
\hline 2 & 0 & 0 & 0 & 30 & -0.453 \\
\hline 3 & 0 & 0 & 0 & 15 & -0.253 \\
\hline 4 & 0 & 0 & 0 & -10 & -0.199 \\
\hline 5 & 10 & 0 & 0 & 0 & -0.081 \\
\hline 6 & 0 & 0 & 10 & 0 & -0.072 \\
\hline 7 & 0 & 0 & 20 & 0 & 0.043 \\
\hline 8 & 0 & 0 & 0 & 10 & -0.009 \\
\hline 9 & 0 & 15 & 0 & 0 & 0.198 \\
\hline 10 & 0 & 0 & 0 & 25 & 0.074 \\
\hline 11 & 0 & 15 & 0 & 0 & 0.235 \\
\hline
\end{tabular}




\section{International Journal of Engineering Applied Sciences and Technology, 2021 \\ Vol. 6, Issue 1, ISSN No. 2455-2143, Pages 265-277 \\ Published Online May 2021 in IJEAST (http://www.ijeast.com)}

Regression Model for predicting Main Rotor Lateral Vibrations of helicopter during ground run is $\hat{\mathrm{Y}}=-0.129+0.005 \mathrm{x}_{1}+$ $0.022 \mathrm{x}_{2}+0.008 \mathrm{x}_{3}-0.002 \mathrm{x}_{4}$. The Multiple $\mathrm{R}$ value of Regression Model is 0.828 . ANOVA of this case of vibration prediction is shown in Table-9.

Case-2: Multiple Linear Regression Model for Prediction of Main Rotor Lateral Vibrations during Flight $\left(\mathrm{X}_{\mathrm{i}}\right.$ - Mass added / removed on MR Blades are inputs and $\Delta \mathrm{Y}$ - Change in MR- Lateral Vibrations are outputs for generating Regression Model using MatLab).

Table-4: Inputs and outputs to MatLab for generate MLR model predicting the MR Lateral Vibrations during flight

\begin{tabular}{|c|c|c|c|c|}
\hline \multicolumn{4}{|c|}{ MR Lateral - Flight (Mass inputs) } & Outputs \\
\hline $\mathrm{X} 1$ & $\mathrm{X} 2$ & $\mathrm{X} 3$ & $\mathrm{X} 4$ & Y120 \\
\hline Red & Yellow & Blue & Green & $\Delta \mathrm{YF}$ \\
\hline 0 & -15 & 0 & 15 & -0.185 \\
\hline 0 & 0 & 0 & 30 & -0.048 \\
\hline 0 & 0 & 0 & 15 & 0.061 \\
\hline 0 & 0 & 0 & -10 & 0.031 \\
\hline 10 & 0 & 0 & 0 & -0.043 \\
\hline 0 & 0 & 10 & 0 & 0.027 \\
\hline 0 & 0 & 20 & 0 & -0.018 \\
\hline 0 & 0 & 0 & 10 & 0.043 \\
\hline 0 & 15 & 0 & 0 & 0.252 \\
\hline 0 & 0 & 0 & 25 & 0.022 \\
\hline 0 & 15 & 0 & 0 & 0.186 \\
\hline
\end{tabular}

Regression Model for predicting Main Rotor Lateral Vibrations of helicopter during flight is $\hat{\mathrm{Y}}=0.037-0.008 \mathrm{x}_{1}+0.013 \mathrm{x}_{2}-$ $0.002 \mathrm{x}_{3}-0.001 \mathrm{x}_{4}$. The Multiple $\mathrm{R}$ value of Regression Model is 0.971 . ANOVA of this case of vibration prediction is shown in Table-10.

Case-3: Multiple Linear Regression Model for Prediction of Main Rotor Vertical Vibrations during Ground Run $\left(\mathrm{X}_{\mathrm{i}}-\mathrm{Tracking}\right.$ Link CW / CCW rotation on MR Blades are inputs and $\Delta \mathrm{Y}$ - Change in MR-Vertical Vibrations are outputs for generating Regression Model using MatLab).

Table-5: Inputs and outputs to MatLab for generate MLR model Predicting the MR Vertical Vibrations during ground run.

\begin{tabular}{|c|c|c|c|c|}
\hline \multicolumn{2}{|c|}{ MR Vertical - Ground (Tracking Link Inputs) } & Outputs \\
\hline X1 & X2 & X3 & X4 & YTL \\
\hline Red & Yellow & Blue & Green & $\Delta$ Y \\
\hline 0.5 & 0 & 0 & 0 & -0.021 \\
\hline-0.5 & 0 & 0 & 0 & 0.091 \\
\hline-0.25 & 0 & 0.5 & 0 & -0.101 \\
\hline 0 & 0 & -0.5 & -0.25 & 0.03 \\
\hline 1 & 0 & -1 & 0 & -0.031 \\
\hline 0 & 0 & 0.5 & 0.4 & 0.03 \\
\hline 0 & 0 & 0.5 & 0.25 & 0.021 \\
\hline 0 & -0.5 & -0.5 & -0.25 & 0.252 \\
\hline 0.5 & -0.25 & 0.25 & 0 & -0.048 \\
\hline 0.5 & -0.25 & 0 & 0.25 & 0.02 \\
\hline 0 & -0.25 & 0.25 & 0 & 0.02 \\
\hline
\end{tabular}

Regression Model for predicting Main Rotor Vertical Vibrations of helicopter during ground run is $\hat{\mathrm{Y}}=0.003-0.182 \mathrm{x}_{1}-0.362 \mathrm{x}_{2}$ $-0.174 \mathrm{x}_{3}+0.233 \mathrm{x}_{4}$. The Multiple $\mathrm{R}$ value of Regression Model is 0.899 . ANOVA of this case of vibration prediction is shown in Table-11. 


\section{International Journal of Engineering Applied Sciences and Technology, 2021 \\ Vol. 6, Issue 1, ISSN No. 2455-2143, Pages 265-277 \\ Published Online May 2021 in IJEAST (http://www.ijeast.com)}

Case-4: Multiple Linear Regression Model for Prediction of Tail Rotor Radial Vibrations during Flight ( $\mathrm{X}_{\mathrm{i}}-\mathrm{Mass}_{\mathrm{s}}$ added / removed on TR Blades are inputs and $\Delta Y$ - Change in TR-Radial Vibrations are outputs for generating Regression Model using MatLab).

Table-6: Inputs and outputs to MatLab for generate MLR model predicting the TR Radial Vibrations during flight

\begin{tabular}{|c|c|c|c|c|}
\hline \multicolumn{4}{|c|}{ TR Radial - Flight (Mass Inputs) } & Outputs \\
\hline $\mathrm{X} 1$ & $\mathrm{X} 2$ & $\mathrm{X} 3$ & $\mathrm{X} 4$ & $\mathrm{Y} 120$ \\
\hline Red & Yellow & Blue & Green & $\Delta \mathrm{Y}$ \\
\hline 0.000 & 0.000 & 5.000 & 0.000 & -0.030 \\
\hline 0.800 & 0.000 & 0.800 & 0.000 & 0.073 \\
\hline 0.000 & 2.000 & 0.000 & 0.000 & -0.026 \\
\hline 1.000 & 0.000 & 1.200 & 0.000 & -0.141 \\
\hline 0.000 & -2.000 & 0.000 & 0.000 & -0.550 \\
\hline 0.000 & 1.000 & 0.000 & 1.600 & 0.241 \\
\hline 1.000 & 0.000 & 0.000 & 0.000 & 0.145 \\
\hline 0.000 & 0.000 & 1.600 & 1.000 & -0.284 \\
\hline
\end{tabular}

Regression Model for predicting Tail Rotor Radial Vibrations of helicopter during flight in $\hat{\mathrm{Y}}=-0.269+0.289 \mathrm{x}_{1}+0.147 \mathrm{x}_{2}+$ $0.028 \mathrm{x}_{3}+0.146 \mathrm{x}_{4}$. The Multiple $\mathrm{R}$ value of Regression Model is 0.839 . ANOVA of this case of vibration prediction is shown in Table-12.

Case-5: Multiple Linear Regression Model for Prediction of Tail Rotor Axial Vibrations during Flight $\left(\mathrm{X}_{\mathrm{i}}-\mathrm{Pitch}_{\mathrm{Link}} \mathrm{CW} /\right.$ $\mathrm{CCW}$ rotation on TR Blades are inputs and $\Delta \mathrm{Y}-$ Change in TR-Axial Vibrations are outputs for generating Regression Model using MatLab).

Table-7: Inputs and outputs to MatLab for generate MLR model predicting the TR Axial Vibrations during flight

\begin{tabular}{|c|c|c|c|c|}
\hline \multicolumn{4}{|c|}{ TR Axial - Flight (Pitch Link Inputs) } & Outputs \\
\hline X1 & X2 & X3 & X4 & Y80 \\
\hline Red & Yellow & Blue & Green & $\Delta \mathrm{Y}$ \\
\hline 0 & 0 & -1 & 0 & -0.13 \\
\hline 0.5 & 0 & -0.5 & 0 & 0.045 \\
\hline 0 & -4 & 0 & 0 & -0.211 \\
\hline 0 & -2 & 0 & -2.5 & -0.103 \\
\hline 0 & 0 & -1.5 & 0 & -0.069 \\
\hline 0 & 0 & 0.5 & -1 & 0.192 \\
\hline 0 & 2.5 & 0 & -2 & 0.299 \\
\hline 0 & 3 & -3 & 0 & -0.209 \\
\hline-3 & 0 & -1 & 3 & -0.386 \\
\hline-3 & -2 & 0 & 0 & 0.007 \\
\hline 0 & 0 & 0 & 3 & 0.019 \\
\hline
\end{tabular}

Regression Model for predicting Tail Rotor Axial Vibrations of helicopter during Flight in $\hat{\mathrm{Y}}=0.077+0.025 \mathrm{x}_{1}+0.068 \mathrm{x}_{2}+$ $0.164 \mathrm{x}_{3}-0.030 \mathrm{x}_{4}$. The Multiple $\mathrm{R}$ value of Regression Model is 0.906 . ANOVA of this case of vibration prediction is shown in Table-13. 


\section{RESULTS, CONCLUSIONS AND RECOMMENDATIONS}

Multiple Linear Regression for Rotor Smoothening Procedure is used to predict the Main Rotor or Tail Rotor vibrations with input parameters in the form of mass changes (in grams), tracking link changes (as flats) and Pitch Link changes (as flats). The output parameter is Change in Vibration of Main Rotor or Tail Rotor. The Vibration data and corrections given during RTB optimization process of helicopters were processed to obtain input and output pairs and were used to develop MLR model using MatLab for predicting change in vibrations of MR and TR. Five types of MLR models were generated for vibration predictions in different regimes of helicopter using MatLab and analyzed for Multiple-R, Rsquared values using data analysis of Excel/Minitab. Corrections to be given for a new vibration conditions were predicted by using the MLR models. The MLR vibration predictions for given inputs were found to be satisfactory. The Coefficient of Regression values achieved was more than 0.9. Summary of Regression models \& Regression Values obtained with MLR Simulation is shown in Table-8. Graphical User Interface for Vibration Predictions of Serviced Helicopter is shown in Fig-5.

Table-8: Summary of Regression Models and Regression values (Multiple-R / R-squared) for Prediction of Regression Models.

\begin{tabular}{|c|c|c|c|c|c|c|c|}
\hline $\begin{array}{l}\text { Sl. } \\
\text { No. }\end{array}$ & MLR model & Purpose & Inputs & Outputs & $\begin{array}{c}\text { Multiple- } \\
\text { R }\end{array}$ & $\begin{array}{c}\text { R- } \\
\text { Squared }\end{array}$ & $\begin{array}{c}\text { Standard } \\
\text { error }\end{array}$ \\
\hline 1 & $\begin{array}{l}\hat{y}=-0.129+0.005 x_{1} \\
+0.022 x_{2}+0.008 x_{3} \\
-0.002 x_{4}\end{array}$ & $\begin{array}{c}\text { MR } \\
\text { Lateral } \\
\text { Ground }\end{array}$ & $\begin{array}{l}\text { Mass in } \\
\text { grams }\end{array}$ & $\begin{array}{c}\text { Prediction of } \\
\text { change in MR } \\
\text { Lateral Ground } \\
\text { Vibration }\end{array}$ & 0.828 & 0.686 & 0.170 \\
\hline 2 & $\begin{array}{c}\hat{\mathrm{y}}=0.037-0.008 \mathrm{x}_{1} \\
+0.013 \mathrm{x}_{2}-0.002 \mathrm{x}_{3} \\
-0.001 \mathrm{x}_{4}\end{array}$ & $\begin{array}{c}\text { MR } \\
\text { Lateral } \\
\text { Flight }\end{array}$ & $\begin{array}{l}\text { Mass in } \\
\text { grams }\end{array}$ & $\begin{array}{c}\text { Prediction of MR } \\
\text { Lateral Flight } \\
\text { Vibrations }\end{array}$ & 0.971 & 0.943 & 0.036 \\
\hline 3 & $\begin{array}{c}\hat{\mathrm{y}}=0.003-0.182 \mathrm{x}_{1} \\
-0.362 \mathrm{x}_{2}-0.174 \mathrm{x}_{3} \\
+0.233 \mathrm{x}_{4}\end{array}$ & $\begin{array}{c}\text { MR } \\
\text { Vertical } \\
\text { Ground }\end{array}$ & $\begin{array}{l}\text { Trackin } \\
\text { g Link } \\
\text { in Flats }\end{array}$ & $\begin{array}{l}\text { Prediction of MR } \\
\text { Vertical Ground } \\
\text { Vibrations }\end{array}$ & 0.899 & 0.808 & 0.051 \\
\hline 4 & $\begin{array}{c}\hat{\mathrm{y}}=- \\
0.2699+0.289 \mathrm{x}_{1}+0 \\
.147 \mathrm{x}_{2}+0.028 \mathrm{x}_{3}+0 . \\
146 \mathrm{x}_{4}\end{array}$ & $\begin{array}{l}\text { TR } \\
\text { Radial } \\
\text { Flight }\end{array}$ & $\begin{array}{l}\text { Mass in } \\
\text { grams }\end{array}$ & $\begin{array}{c}\text { Prediction of TR } \\
\text { Radial Flight } \\
\text { Vibrations }\end{array}$ & 0.839 & 0.703 & 0.211 \\
\hline 5 & $\begin{array}{c}\hat{\mathrm{y}}=0.077+0.025 \mathrm{x}_{1} \\
+0.068 \mathrm{x}_{2}+0.164 \mathrm{x}_{3} \\
-0.030 \mathrm{x}_{4}\end{array}$ & $\begin{array}{c}\text { TR } \\
\text { Axial } \\
\text { Flight }\end{array}$ & $\begin{array}{l}\text { Pitch } \\
\text { Link in } \\
\text { Flats }\end{array}$ & $\begin{array}{c}\text { Prediction of TR } \\
\text { Axial Flight } \\
\text { Vibrations }\end{array}$ & 0.906 & 0.821 & 0.105 \\
\hline
\end{tabular}

\section{IX.FUTURE WORK}

Similar Study can be done for batch of new helicopters for generation of Vibration data at regular $300 \mathrm{hrs}$ intervals from Induction date. Intervals - 0 to 300,300 to 600,600 to 900 and so on. The generated vibration data can be fed to database for standardization of MLR Model to entire Helicopter Fleet And, using dynamic vibration data for MLR / MVLR modelling and generating the more precise regression coefficients may be taken up for future study. MVLR models can be generated for vibration predictions of all other regimes. GUI shown may be improved to for Vibration Predictions based on Dynamic Sensitivity Coefficients with dynamic vibration data observed during RTB optimization.

\section{ACKNOWLEDGEMENTS}

I would like to express my sincere appreciation to my faculty advisor, Co-Author, Professor Dr. A. Gopalakrishna, Director, R\&D, JNTU, Kakinada, for sharing his knowledge and providing advice throughout the course. I would also like to thank the management of Helicopter MRO Division for giving me permission to carryout research and Ms. Rekha Nagaraj, DGM (QA)-MRO, Mr. Sridhar S, HOD-DYN, Rotary Wing Research \& Design Center and their team for providing necessary technical guidance on helicopter and confidence in regular progress during the course of this research work.

\section{REFERENCES}

[1] Lawrence Jerome, October 2009, "Multiple Linear and Non-Linear Regression in Minitab".

[2] Y.S.Kong, S.Abdullah, D.Schramm, M.Z.Omar, S.M.Haris, Sept 2018, "Development of Multiple Linear Regression based models for Fatigue Life evaluation of Automotive Coil Springs".

[3] John Vine, Xiaobo Yu, 2012, "Load synthesis of helicopter dynamic components: Improvements to Linear Regression in the Azimuth domain". 
[4] Sunghae Jun, Jacob Wood, Sangsung Park, April 2017, "Multivariate Multiple Regression modelling of technology analysis".

[5] Mehmet Mendes, March 2011, "Multivariate Multiple Regression analysis based on principal component scores to study relationships between some pre- and postslaughter Traits of Boiler".

[6] Kanchan Jain, Sukhbir Singh, Suresh Sharma, Sep 2010, "Restricted estimation in multivariate measurement error regression model".

[7] Alexopoulos EC, 2010, "Introduction to Multivariate Regression Analysis".

[8] Dr. Chris Tofallis, 1999, "Model building with multiple dependent variables and constraints".

[9] Lambert Z.V., Wildt A.R., Durand R.M., 2016, “An alternative to canonical correlation and multivariate multiple regression in exploring interset associations".

[10] Somayeh Asad, Shideh Shams Amiri, Mohammad Mottahedi, July 2014, "On the Development of MultiLinear Regression Analysis to Assess Energy Consumption in the Early Stages of Building Design".

[11] Tiberiu Catalina, Vlad lordache, Bogdan Caracaleanu, Nov 2012, "Multiple regression model for fast prediction of the heating energy demand".
[12] Nelson Fumon, M.A. Rafe Biswas, March 2015, "Regression analysis for prediction of residential energy consumption".

[13] Daniel Martinez, Wesley Brewer, Andrew Strelzoff, Andrew Wilson, Daniel Wade, Aug 2019, "Rotorcraft Virtual Sensors via Deep Regression".

[14] Miguel Prieto, Peter Tanner, Carmen Andrade, Feb 2016, "Multiple Linear Regression model for the assessment of bond strength in corroded and non-corroded steel bars in structural concrete".

[15] Kyungtae Yun, Rogelio Luck, Pedro J Mago, Heejin Cho, March 1999, "Building hourly thermal load prediction using an indexed ARX model".

[16] Max Lier DLR, Aug 2012, "Statistical Methods for Helicopter Preliminary Design and Sizing".

[17] https://hal-india.co.in/Production\%20Units/M89

Table-2: Matlab code for evaluation of regression coefficients for Regression Models using MatLab:

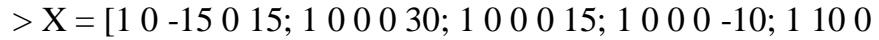
$00 ; 100100 ; 100200 ; 1000$ 10; $101500 ; 100025 ; 1$

$\left.\begin{array}{llll}0 & 15 & 0 & 0\end{array}\right]$

$>\mathrm{Y}=[-0.463 ;-0.453 ;-0.253 ;-0.199 ;-0.081 ;-0.072 ; 0.043 ;-$ $0.009 ; 0.198 ; 0.074 ; 0.235]$

$>\mathrm{B}=\operatorname{inv}\left(\left(\mathrm{X}^{\prime *} \mathrm{X}\right)\right) * \mathrm{X}^{\prime * \mathrm{Y}}$.

FIGURES

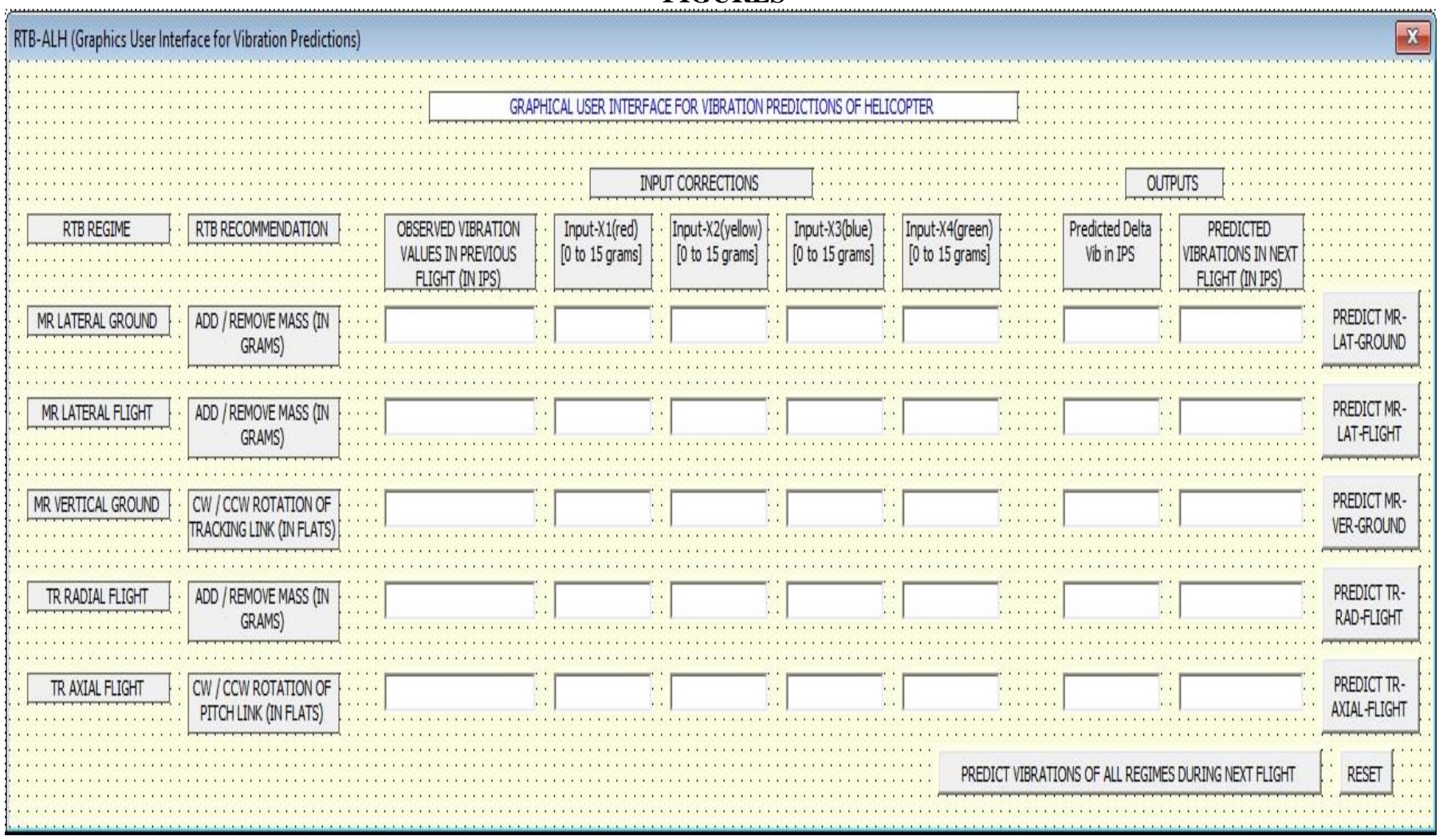

Fig-5: Graphical User Interface for Vibration Predictions of Helicopter. 


\section{TABLES}

ANOVA of Case-1: Multiple Linear Regression Model for Prediction of Main Rotor Lateral Vibrations during Ground Run.

Table-9: Testing of Regression model using R-Language / data analysis of Excel.

\begin{tabular}{|c|c|}
\hline \multicolumn{2}{|c|}{ Regression Statistics } \\
\hline Multiple R & 0.828 \\
\hline R Square & 0.686 \\
\hline Adjusted R Square & 0.476 \\
\hline Standard Error & 0.170 \\
\hline Observations & 11 \\
\hline
\end{tabular}

ANOVA
\begin{tabular}{|c|c|c|c|c|c|}
\hline & $d f$ & $S S$ & $M S$ & $F$ & Significance $F$ \\
\hline Regression & 4 & 0.377 & 0.094 & 3.272 & 0.095 \\
\hline Residual & 6 & 0.173 & 0.029 & & \\
\hline Total & 10 & 0.549 & & & \\
\hline
\end{tabular}

\begin{tabular}{|c|c|c|c|c|c|c|c|c|}
\hline & Coefficients & $\begin{array}{c}\text { Standard } \\
\text { Error }\end{array}$ & $t$ Stat & P-value & $\begin{array}{c}\text { Lower } \\
95 \%\end{array}$ & Upper 95\% & $\begin{array}{c}\text { Lower } \\
95 \%\end{array}$ & Upper 95\% \\
\hline Intercept & -0.129 & 0.085 & -1.519 & 0.180 & -0.336 & 0.079 & -0.336 & 0.079 \\
\hline $\mathrm{X} 1$ & 0.005 & 0.019 & 0.252 & 0.810 & -0.042 & 0.051 & -0.042 & 0.051 \\
\hline $\mathrm{X} 2$ & 0.022 & 0.007 & 3.009 & 0.024 & 0.004 & 0.040 & 0.004 & 0.040 \\
\hline $\mathrm{X} 3$ & 0.008 & 0.009 & 0.876 & 0.415 & -0.014 & 0.030 & -0.014 & 0.030 \\
\hline $\mathrm{X} 4$ & -0.002 & 0.005 & -0.415 & 0.693 & -0.015 & 0.011 & -0.015 & 0.011 \\
\hline
\end{tabular}

ANOVA of Case-2: Multiple Linear Regression Model for Prediction of Main Rotor Lateral Vibrations during Flight.

Table-10: Testing of Regression model using R-Language / data analysis of Excel.

\begin{tabular}{|c|c|}
\hline \multicolumn{2}{|c|}{ Regression Statistics } \\
\hline Multiple R & 0.971 \\
\hline R Square & 0.943 \\
\hline Adjusted R Square & 0.904 \\
\hline Standard Error & 0.036 \\
\hline Observations & 11 \\
\hline
\end{tabular}

\section{ANOVA}

\begin{tabular}{|c|r|c|c|c|r|}
\hline & $d f$ & $S S$ & $M S$ & $F$ & Significance $F$ \\
\hline Regression & 4 & 0.127 & 0.032 & 24.640 & 0.001 \\
\hline Residual & 6 & 0.008 & 0.001 & & \\
\hline Total & 10 & 0.135 & & & \\
\hline
\end{tabular}


International Journal of Engineering Applied Sciences and Technology, 2021

Vol. 6, Issue 1, ISSN No. 2455-2143, Pages 265-277

Published Online May 2021 in IJEAST (http://www.ijeast.com)

\begin{tabular}{|c|c|c|c|c|c|c|c|c|}
\hline & Coefficients & $\begin{array}{c}\text { Standard } \\
\text { Error }\end{array}$ & $t$ Stat & P-value & $\begin{array}{c}\text { Lower } \\
95 \%\end{array}$ & $\begin{array}{c}\text { Upper } \\
95 \%\end{array}$ & $\begin{array}{c}\text { Lower } \\
95 \%\end{array}$ & $\begin{array}{c}\text { Upper } \\
95 \%\end{array}$ \\
\hline Intercept & 0.037 & 0.018 & 2.058 & 0.085 & -0.007 & 0.081 & -0.007 & 0.081 \\
\hline X1 & -0.008 & 0.004 & -1.991 & 0.094 & -0.018 & 0.002 & -0.018 & 0.002 \\
\hline X2 & 0.013 & 0.002 & 8.106 & 0.000 & 0.009 & 0.016 & 0.009 & 0.016 \\
\hline X3 & -0.002 & 0.002 & -1.239 & 0.262 & -0.007 & 0.002 & -0.007 & 0.002 \\
\hline X4 & -0.001 & 0.001 & -1.231 & 0.265 & -0.004 & 0.001 & -0.004 & 0.001 \\
\hline
\end{tabular}

ANOVA of Case-3: Multiple Linear Regression Model for Prediction of Main Rotor Vertical Vibrations during Ground.

Table-11: Testing of Regression model using R-Language / data analysis of Excel.

\begin{tabular}{|c|c|}
\hline \multicolumn{2}{|c|}{ Regression Statistics } \\
\hline Multiple R & 0.899 \\
\hline R Square & 0.808 \\
\hline Adjusted R Square & 0.680 \\
\hline Standard Error & 0.051 \\
\hline Observations & 11 \\
\hline
\end{tabular}

ANOVA

\begin{tabular}{|c|c|c|c|c|c|}
\hline & $d f$ & $S S$ & $M S$ & $F$ & Significance $F$ \\
\hline Regression & 4 & 0.067 & 0.017 & 6.302 & 0.024 \\
\hline Residual & 6 & 0.016 & 0.003 & & \\
\hline Total & 10 & 0.082 & & & \\
\hline
\end{tabular}

\begin{tabular}{|c|c|c|c|c|c|c|c|c|}
\hline & Coefficients & $\begin{array}{c}\text { Standard } \\
\text { Error }\end{array}$ & $t$ Stat & P-value & $\begin{array}{c}\text { Lower } \\
95 \%\end{array}$ & Upper 95\% & $\begin{array}{c}\text { Lower } \\
95 \%\end{array}$ & $\begin{array}{c}\text { Upper } \\
95 \%\end{array}$ \\
\hline Intercept & 0.003 & 0.021 & 0.157 & 0.881 & -0.047 & 0.054 & -0.047 & 0.054 \\
\hline Red & -0.182 & 0.052 & -3.487 & 0.013 & -0.309 & -0.054 & -0.309 & -0.054 \\
\hline Yellow & -0.362 & 0.101 & -3.569 & 0.012 & -0.610 & -0.114 & -0.610 & -0.114 \\
\hline Blue & -0.174 & 0.056 & -3.117 & 0.021 & -0.310 & -0.037 & -0.310 & -0.037 \\
\hline Green & 0.233 & 0.125 & 1.861 & 0.112 & -0.073 & 0.540 & -0.073 & 0.540 \\
\hline
\end{tabular}

ANOVA of Case-4: Multiple Linear Regression Model for Prediction of Tail Rotor Radial Vibrations during Flight.

Table-12: Testing of Regression model using R-Language / data analysis of Excel.

\begin{tabular}{|c|c|}
\hline \multicolumn{2}{|c|}{ Regression Statistics } \\
\hline Multiple R & 0.839 \\
\hline R Square & 0.703 \\
\hline Adjusted R Square & 0.308 \\
\hline Standard Error & 0.211 \\
\hline Observations & 8 \\
\hline
\end{tabular}


International Journal of Engineering Applied Sciences and Technology, 2021

Vol. 6, Issue 1, ISSN No. 2455-2143, Pages 265-277

Published Online May 2021 in IJEAST (http://www.ijeast.com)

ANOVA

\begin{tabular}{|c|c|c|c|c|c|}
\hline & $d f$ & $S S$ & $M S$ & $F$ & Significance $F$ \\
\hline Regression & 4 & 0.315 & 0.079 & 1.778 & 0.332 \\
\hline Residual & 3 & 0.133 & 0.044 & & \\
\hline Total & 7 & 0.448 & & & \\
\hline
\end{tabular}

\begin{tabular}{|c|c|c|c|c|c|c|c|c|}
\hline & Coefficients & $\begin{array}{c}\text { Standard } \\
\text { Error }\end{array}$ & $t$ Stat & P-value & $\begin{array}{c}\text { Lower } \\
95 \%\end{array}$ & $\begin{array}{c}\text { Upper } \\
95 \%\end{array}$ & $\begin{array}{c}\text { Lower } \\
95 \%\end{array}$ & $\begin{array}{c}\text { Upper } \\
95 \%\end{array}$ \\
\hline Intercept & -0.269 & 0.147 & -1.824 & 0.166 & -0.737 & 0.200 & -0.737 & 0.200 \\
\hline Red & 0.289 & 0.190 & 1.522 & 0.225 & -0.315 & 0.893 & -0.315 & 0.893 \\
\hline Yellow & 0.147 & 0.073 & 2.008 & 0.138 & -0.086 & 0.380 & -0.086 & 0.380 \\
\hline Blue & 0.028 & 0.050 & 0.564 & 0.612 & -0.130 & 0.186 & -0.130 & 0.186 \\
\hline Green & 0.146 & 0.151 & 0.965 & 0.406 & -0.335 & 0.627 & -0.335 & 0.627 \\
\hline
\end{tabular}

ANOVA of Case-5: Multiple Linear Regression Model for Prediction of Tail Rotor Axial Vibrations during Flight.

Table-13: Testing of Regression model using R-Language / data analysis of Excel.

\begin{tabular}{|c|c|}
\hline $\begin{array}{c}\text { Regression } \\
\text { Statistics }\end{array}$ & \\
\hline Multiple R & 0.906 \\
\hline R Square & 0.821 \\
\hline Adjusted R Square & 0.701 \\
\hline Standard Error & 0.105 \\
\hline Observations & 11 \\
\hline
\end{tabular}

ANOVA

\begin{tabular}{|c|c|c|c|c|c|}
\hline & $d f$ & $S S$ & $M S$ & $F$ & Significance $F$ \\
\hline Regression & 4 & 0.304 & 0.076 & 6.857 & 0.020 \\
\hline Residual & 6 & 0.067 & 0.011 & & \\
\hline Total & 10 & 0.371 & & & \\
\hline
\end{tabular}

\begin{tabular}{|c|c|c|c|c|c|c|c|c|}
\hline & Coefficients & $\begin{array}{c}\text { Standard } \\
\text { Error }\end{array}$ & t Stat & P-value & $\begin{array}{c}\text { Lower } \\
95 \%\end{array}$ & $\begin{array}{c}\text { Upper } \\
95 \%\end{array}$ & $\begin{array}{c}\text { Lower } \\
95 \%\end{array}$ & $\begin{array}{c}\text { Upper } \\
95 \%\end{array}$ \\
\hline Intercept & 0.077 & 0.044 & 1.752 & 0.130 & -0.030 & 0.184 & -0.030 & 0.184 \\
\hline Red & 0.025 & 0.030 & 0.822 & 0.443 & -0.049 & 0.098 & -0.049 & 0.098 \\
\hline Yellow & 0.068 & 0.020 & 3.331 & 0.016 & 0.018 & 0.118 & 0.018 & 0.118 \\
\hline Blue & 0.164 & 0.041 & 4.047 & 0.007 & 0.065 & 0.264 & 0.065 & 0.264 \\
\hline Green & -0.030 & 0.022 & -1.361 & 0.222 & -0.084 & 0.024 & -0.084 & 0.024 \\
\hline
\end{tabular}

